\title{
Ethyl (2-cyano-3-ethoxyacryloyl)carbamate: irreversible thermal isomerization of a push-pull olefin
}

\author{
Kuangsen Sung*, Ming-Chi Lin, Pin-Mei Huang, Bo-Ren Zhuang, Robert Sung, \\ and Ru-Rong Wu \\ Department of Chemistry, National Cheng Kung University, Tainan, Taiwan \\ ${ }^{\dagger}$ Current address: Riverside Secondary School, 2215 Reeve Street, Port Coquitlam, B.C., \\ Canada, V3C 6 K8 \\ E-mail: kssung@mail.ncku.edu.tw \\ (received 09 Mar 05; accepted 19 Apr 05; published on the web 20 Apr 05)
}

\begin{abstract}
A push-pull olefin, E-2, was prepared highly stereoselectively by reaction of ethyl (2cyanoacetyl)carbamate, $\mathbf{1}$, with ethyl orthoformate in the presence of acetic anhydride. Forty percent of E-2 was isomerized to Z-2 after two hours of irradiation at $254 \mathrm{~nm}$. All the Z-2 was isomerized back to $E-2$ spontaneously and irreversibly with $\mathrm{Ea}=19.6 \mathrm{kcal} \mathrm{mol}^{-1}, \Delta \mathrm{H}^{\ddagger}=19.0 \mathrm{kcal}$ $\mathrm{mol}^{-1}, \Delta \mathrm{S}^{*}=-17.5 \mathrm{cal} \mathrm{K}^{-1} \mathrm{~mol}^{-1}$, and $\Delta \mathrm{G}^{*}=24.4 \mathrm{kcal} \mathrm{mol}^{-1}$. The negative entropy of activation for this isomerization indicates that the transition state has much more charge separation than the ground state. The low rotational barrier of this isomerization and very big chemical shift difference $\left(\Delta \delta_{\mathrm{C}=\mathrm{C}}=85.83 \mathrm{ppm}\right)$ of two $\mathrm{sp}^{2}$-hybridized carbons of $\mathrm{C}=\mathrm{C}$ partial double bond confirm 2 is a push-pull olefin.
\end{abstract}

Keywords: Isomerization, push-pull olefin

\section{Introduction}

5-Fluorouracil is an effective antitumor agent ${ }^{1}$ and we are trying to prepare its derivatives by multi-component reaction (MCR). ${ }^{2}$ To prepare an intermediate to the uracil derivatives, ethyl (2cyanoacetyl)carbamate, $\mathbf{1}$, was treated with ethyl orthoformate in the presence of acetic anhydride in our laboratory, and only E-ethyl (2-cyano-3-ethoxyacryloyl)carbamate, E-2, was found. In addition, we found that isomerization of E-2 to Z-2 is driven only by ultraviolet light while the backward isomerization can be driven by heat. On the other hand, when we treated ethyl acetoacetate with ethyl orthoformate and acetic anhydride, both E-3 and Z-3 were obtained at a ratio of 1:1. Even though both 2 and 3 are push-pull olefins, Z-E isomerization equilibrium of $\mathbf{2}$ is completely different from that of $\mathbf{3}$. 
$Z-E$ isomerization of some alkenes by light or chiral light may function like molecular switch or motor and has applications in optical data storage system, image processor, laser-addressable device, erasable optical recording support, and so on. ${ }^{3}$ It turns out that 2 can be a prototype of molecular switch. Dynamic NMR spectroscopy has been used to determine rotational barriers of push-pull olefins, but the rotational barriers of push-pull olefins with only one geometric isomer detected, such as 2, cannot be measured by the DNMR. ${ }^{4}$ Therefore, both UV and NMR spectrometers were used to study the $Z-E$ isomerization of $\mathbf{2}$ in this article.<smiles>CCCCC(C)C(C)C(C)C</smiles><smiles>C#CCOC(=O)NC(=O)/C=C/OCC</smiles><smiles>CCOC=C(C#N)C(=O)NC(=O)OCC</smiles>

E-2

Z-2

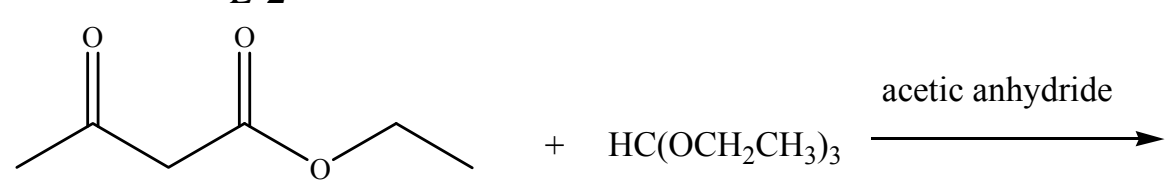<smiles>CCOC=C(C(C)=O)C(=O)OCC</smiles>

E-3<smiles>CCOC(=O)C(C=O)C(C)=O</smiles>

Z-3

\section{Results and Discussion}

Reaction of 1 with ethyl orthoformate in the presence of acetic anhydride in chloroform was carried out under reflux for 2 hours, and only E-2 was isolated in 75\% yield. No trace of Z-2 has been found. The E-2 is well characterized by its ${ }^{1} \mathrm{H}$ and ${ }^{13} \mathrm{C}$ NMR spectra. Its vinyl proton has characteristic resonance absorption at $\delta$ 8.17. The ${ }^{3} \mathrm{~J}$ coupling constant between the vinyl proton 
and nitrile carbon is $11 \mathrm{~Hz}$ while the one between the vinyl proton and amide carbon is $2 \mathrm{~Hz}$. Electrons delocalize preferentially through trans configuration, and this is confirmed by much larger vicinal spin-spin coupling/interaction for trans than for cis configurations in NMR spectra. ${ }^{5}$ It indicates that the vinyl proton of the isolated product is trans to the nitrile group and its structure is E-2, instead of Z-2. NOESY (Figure 1) of the isolated product provides another evidence to support that its configuration is E-2. In the NOESY, vinyl proton at $\delta 8.17$ correlates with both imide proton at $\delta 9.12$ and methylene protons ( $\delta 4.39)$ of ester group, while methylene protons $(\delta 4.12)$ of vinyl ether don't correlate with both vinyl proton at $\delta 8.17$ and imide proton at $\delta$ 9.12. The configuration assignment for $E-2$ is consistent with the one for $E-4$ Ceder and Stenhede did. ${ }^{6}$ Compounds 5 $\mathbf{8}$ were also prepared highly stereoselectively with one geometric isomer isolated, but their configurations were not assigned. ${ }^{4 a}$
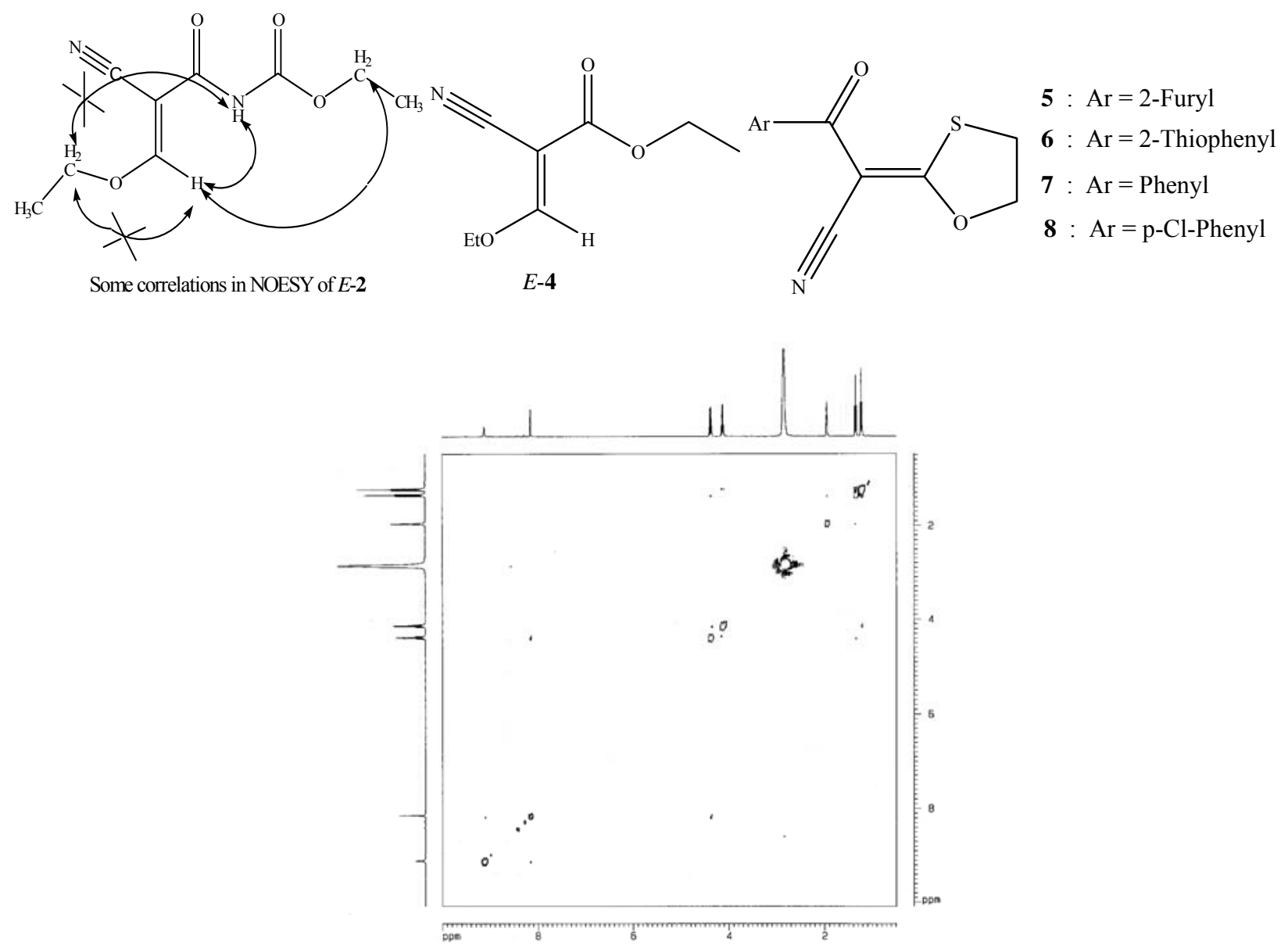

Figure 1. NOESY of E-2 in $\mathrm{CD}_{3} \mathrm{CN}$. 
After $E-2$ in $\mathrm{CD}_{3} \mathrm{CN}$ has been subjected to 2 hours of irradiation at $\lambda=254 \mathrm{~nm}$, intensity of the vinyl proton resonance absorption at $\delta 8.17$ decreases and another resonance absorption at $\delta$ 7.80 appears. After stopping the irradiation, the peak at $\delta 7.80$ disappears slowly while intensity of the original peak at $\delta 8.17$ increases, indicating that the resonance absorption at $\delta 7.80$ belongs to the vinyl proton of Z-2. (Figure 2)

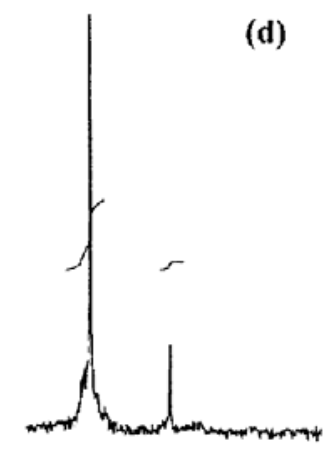

(c)

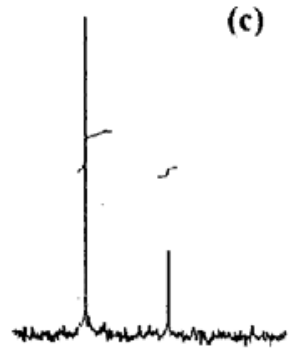

(b)

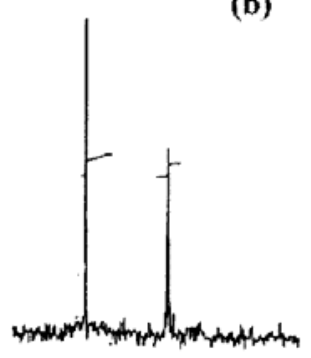

(a)

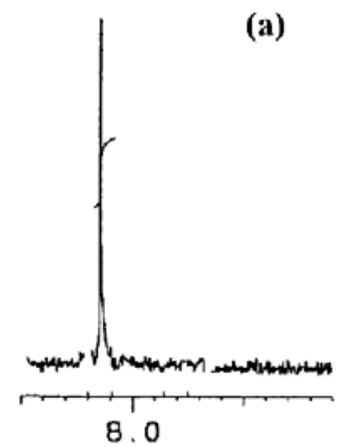

Figure 2. Part of ${ }^{1} \mathrm{H}$ NMR spectra of $E-2$ in $\mathrm{CD}_{3} \mathrm{CN}$ measured (a) before ultraviolet irradiation, (b) $5 \mathrm{~min}$, (c) $10 \mathrm{hrs}$, and (d) 1 day after $2 \mathrm{hrs}$ irradiation at $254 \mathrm{~nm}$. 
Around $40 \%$ of E-2 was isomerized to Z-2 after 2 hours of ultraviolet irradiation at a wavelength of $254 \mathrm{~nm}$. Ultraviolet spectrum of the whole sample in acetonitrile displayed a blue shift. Two days after stopping the irradiation, most of Z-2 was isomerized back to E-2 at room temperature, and ultraviolet spectrum of the sample shifted back to original position (red shift). The isomerization is faster at higher temperature.

After 2 hours of photo-isomerization at $\lambda=254 \mathrm{~nm}$, the mixture of $E-2$ and $Z-2$ was used for kinetic study of the isomerization of Z-2 back to $E$-2. The isomerization in acetonitrile at $25^{\circ} \mathrm{C}$ was monitored by UV spectrophotometer at $\lambda=272 \mathrm{~nm}$, where both isomers have the biggest absorption difference, at six different short time intervals distributed evenly throughout the whole isomerization. The plots of absorption vs. time are fitted with a first-order exponential rise very well and they are shown in Figures 3 and 4. The kinetic studies were carried out at 25, 30, 35,40 , and $45^{\circ} \mathrm{C}$, respectively, and the corresponding rate constants are shown in Table 1 . The Ea, $\Delta \mathrm{H}^{\ddagger}, \Delta \mathrm{S}^{\ddagger}$, and $\Delta \mathrm{G}^{\ddagger}$ for the isomerization of $Z-2$ to $E-2$ were determined to be $19.6 \mathrm{kcal} \mathrm{mol}^{-1}$, $19.0 \mathrm{kcal} \mathrm{mol}^{-1},-17.5 \mathrm{cal} \mathrm{K}^{-1} \mathrm{~mol}^{-1}$, and $24.4 \mathrm{kcal} \mathrm{mol}^{-1}$ according to the Eyring equation. ${ }^{7}$

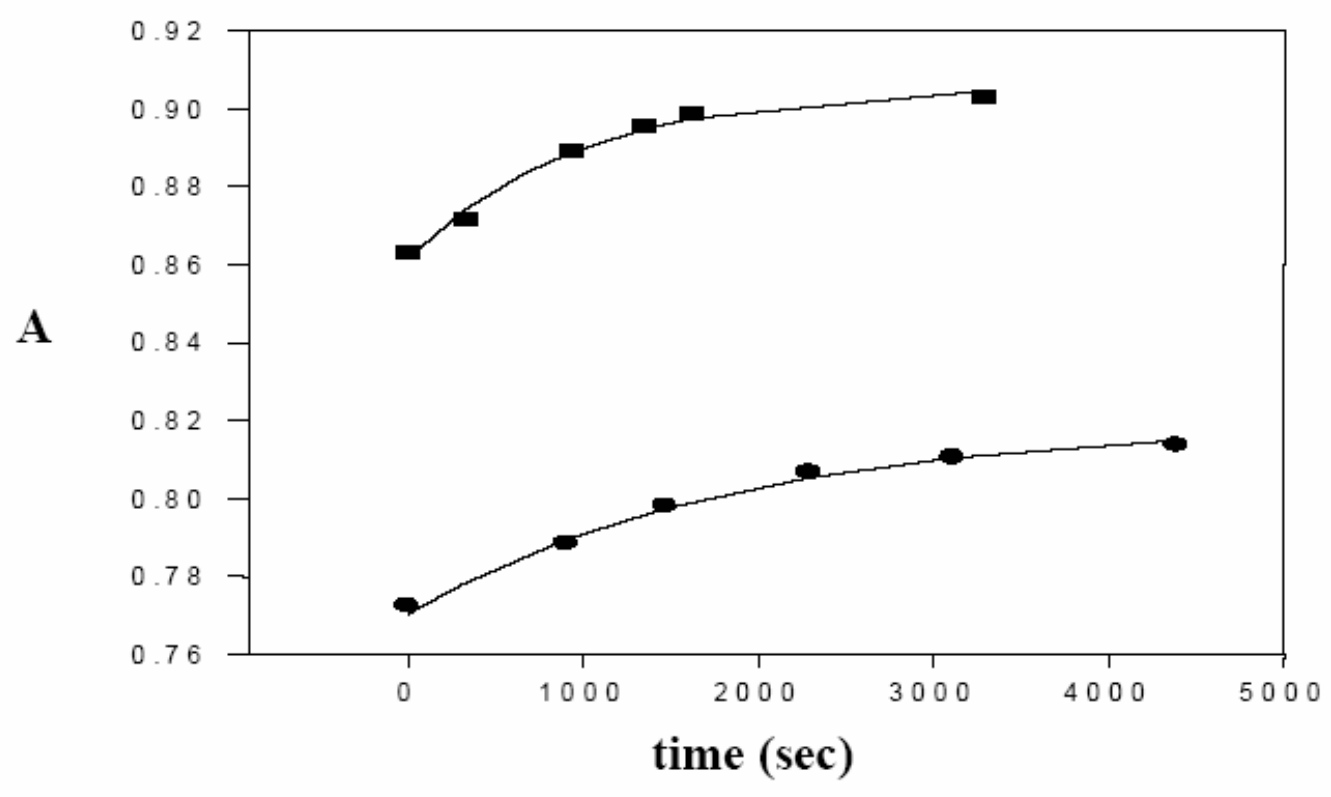

Figure 3. Plots of absorption vs. time for the isomerization of Z-2 to $E-2$ at $25(\bullet)$ and $30{ }^{\circ} \mathrm{C}(\mathbf{\square})$ and their curve fitting with first-order exponential rise by SigmaPlot. 


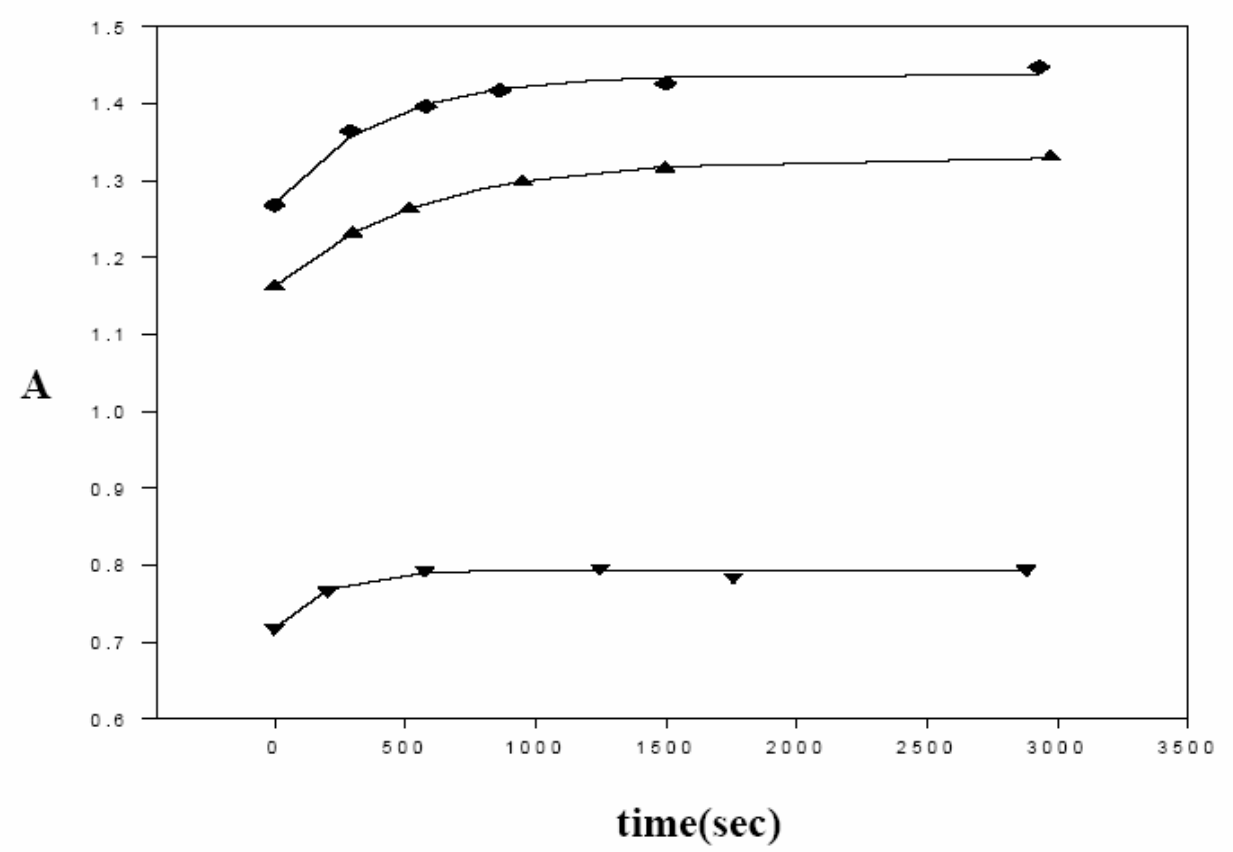

Figure 4. Plots of absorption vs. time for the isomerization of Z-2 to $E-2$ at $35(\Delta), 40(\bullet), 45^{\circ} \mathrm{C}$ $(\boldsymbol{\nabla})$ and their curve fitting with first-order exponential rise by SigmaPlot.

Table 1. Observed Rate Constants for Isomerization of Z-2 to E-2

\begin{tabular}{lccccc}
\hline Temp. $\left({ }^{\circ} \mathrm{C}\right)$ & 25 & 30 & 35 & 40 & 45 \\
\hline $\mathrm{k}_{\mathrm{obs}}\left(\mathrm{s}^{-1}\right)$ & $1.05 \times 10^{-5}$ & $1.71 \times 10^{-5}$ & $3.15 \times 10^{-5}$ & $5.03 \times 10^{-5}$ & $8.28 \times 10^{-5}$ \\
\hline
\end{tabular}

It was reported that reactions generating electric charge exhibit negative entropies of activation. ${ }^{8}$ For example, solvolysis of t-butyl chloride in $80 \%$ aqueous ethanol displays negative entropy of activation $\left(-6.6 \mathrm{cal} \mathrm{K}^{-1} \mathrm{~mol}^{-1}\right)$ even though two particles are being generated from one in the transition state. ${ }^{9}$ Similarly, negative entropy of activation $\left(-17.5 \mathrm{cal} \mathrm{K}^{-1} \mathrm{~mol}^{-1}\right)$ for the isomerization of Z-2 to $E-2$ indicates that the transition state has much more charge separation than the ground state. Because of more polar character, the transition state requires a greater degree of ordering of solvent molecules than the ground state, ${ }^{9}$ leading to the negative entropy of activation.

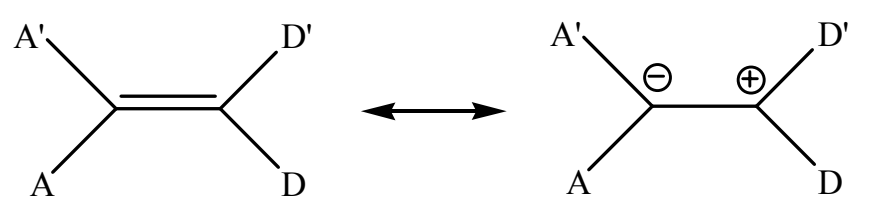

push-pull olefin 
Rotational barriers in alkyl-substituted ethylenes are $>55 \mathrm{kcal} \mathrm{mol}^{-1},{ }^{10}$ while those of pushpull olefins, whose $\pi$-bonds are dramatically polarized, ${ }^{11}$ are significantly lowered and shown in Table 2. ${ }^{4 \mathrm{a}}$ Rotational barrier $\left(\Delta \mathrm{G}^{*}=24.4 \mathrm{kcal} \mathrm{mol}^{-1}\right)$ of the isomerization of Z-2 to $E-2$ is much lower than those of the alkyl-substituted ethylenes, indicating that Z-2 is a push-pull olefin. However, the rotational barrier of Z-2 is around $9.4 \mathrm{kcal} \mathrm{mol}^{-1}$ higher than those $\left(\Delta \mathrm{G}^{*}=9.9 \sim\right.$ $15.0 \mathrm{kcal} \mathrm{mol}^{-1}$ ) of push-pull olefins $\mathbf{9} \sim \mathbf{1 2}$. It was reported that the sequence of $\pi$-donating ability is $\mathrm{N}>\mathrm{S}>\mathrm{O}$. ${ }^{4 a}$ Compounds $\mathbf{9} \sim \mathbf{1 2}$ all have two strong $\pi$-donors $(\mathrm{N})$ while Z-2 has only one less strong $\pi$-donor $(\mathrm{O})$. Therefore, it is reasonable that the rotational barrier of $Z$-2 is much higher than those of $\mathbf{9} \sim \mathbf{1 2}$.

Table 2. Barrier of Rotation, $\Delta \mathrm{G}^{\ddagger}(\mathrm{kcal} / \mathrm{mol})$, about the Central $\mathrm{C}=\mathrm{C}$ Partial Double Bond of Push-pull Olefins in Acetone

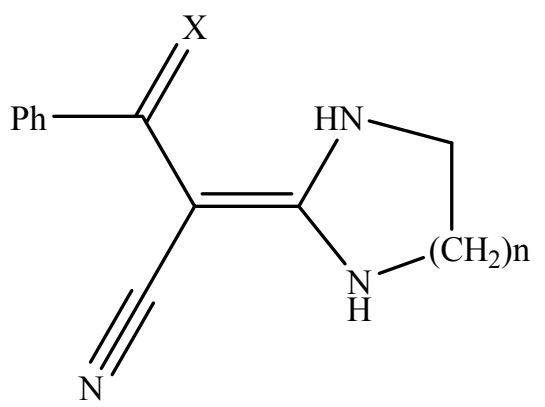

$$
\begin{array}{r}
9: X=O, n=1 \\
10: X=O, n=2 \\
11: X=O, n=3 \\
12: X=S, n=1
\end{array}
$$

\begin{tabular}{ccccc}
\hline Compound & $\mathbf{9}$ & $\mathbf{1 0}$ & $\mathbf{1 1}$ & $\mathbf{1 2}$ \\
\hline$\Delta \mathrm{G}^{\ddagger}$ & 15.0 & 12.3 & 12.7 & 9.9 \\
\hline
\end{tabular}

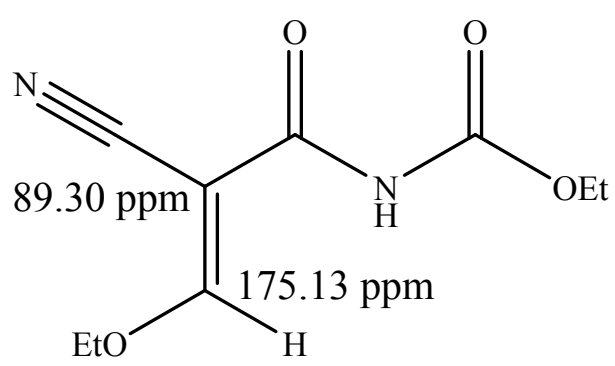

${ }^{13} \mathrm{C}$ NMR of $E-2$

Push-pull effect of olefins can be recognized by both rotational barrier and chemical shift difference $\left(\Delta \delta_{\mathrm{C}=\mathrm{C}}\right)$ of two $\mathrm{sp}^{2}$-hybridized carbons of $\mathrm{C}=\mathrm{C}$ partial double bond. ${ }^{4}$ Due to dramatically polarized $\pi$-bonds, ${ }^{11}$ push-pull olefins display a deshielding effect on the alkenyl carbon of donor side and a shielding effect on the alkenyl carbon of acceptor side, causing $\Delta \delta_{\mathrm{C}=\mathrm{C}}$ being around $82 \sim 100 \mathrm{ppm}^{4}$ The $\Delta \delta_{\mathrm{C}=\mathrm{C}}$ of $E-2$ is $85.83 \mathrm{ppm}$ in $\mathrm{CD}_{3} \mathrm{CN}$, and that confirms 2 is a push-pull olefin. 


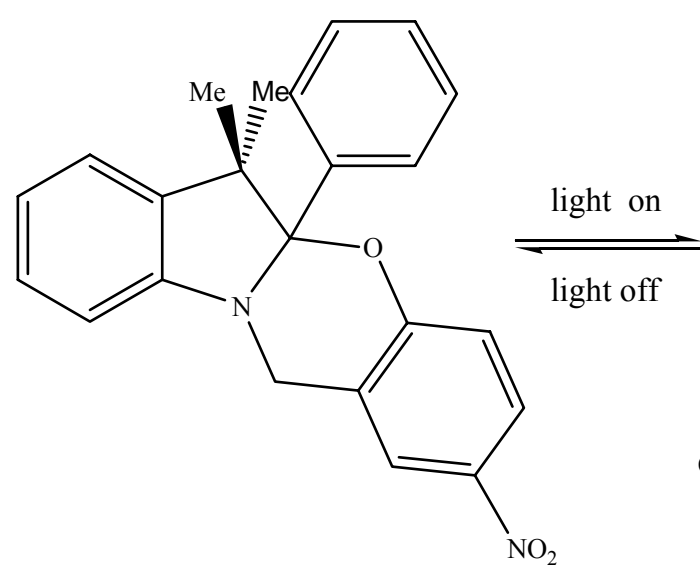

13

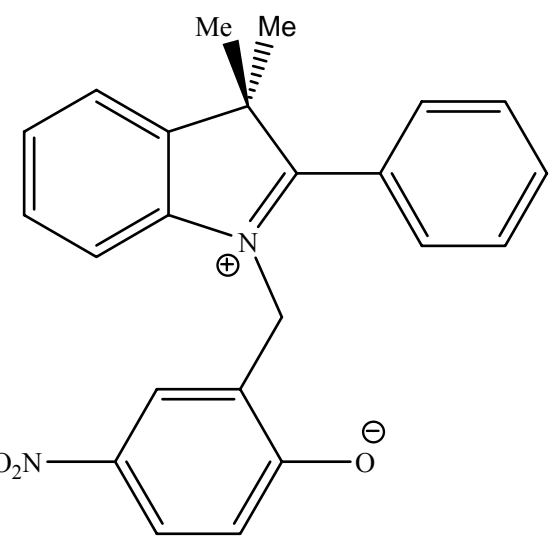

14

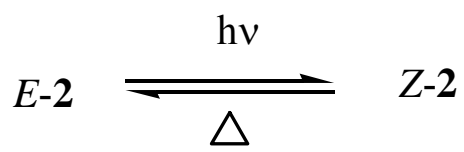

It was reported that $\mathbf{1 3} / \mathbf{1 4}$ are good molecular switches, whose isomerization equilibrium can be driven by light for the forward equilibrium and by heat for the backward isomerization. ${ }^{3 \mathrm{c}} Z-E$ isomerization equilibrium of $\mathbf{2}$ can be driven by the same way, so $\mathbf{2}$ is a prototype of molecular switch. Next challenge of this issue is to modify structure of $\mathbf{2}$ in order to make response time of the system as short as possible.

\section{Conclusions}

The highly stereoselective reaction of $\mathbf{1}$ with ethyl orthoformate in the presence of acetic anhydride produces $E$-2 only. 2 is a push-pull olefin and E-2 is much more stable than Z-2. The Ea, $\Delta \mathrm{H}^{*}, \Delta \mathrm{S}^{\ddagger}$, and $\Delta \mathrm{G}^{*}$ for the isomerization of $\mathrm{Z}-2$ to $E-2$ were determined to be $19.6 \mathrm{kcal} \mathrm{mol}^{-1}$, $19.0 \mathrm{kcal} \mathrm{mol}^{-1},-17.5 \mathrm{cal} \mathrm{K}^{-1} \mathrm{~mol}^{-1}$, and $24.4 \mathrm{kcal} \mathrm{mol}^{-1}$. The negative entropy of activation for this isomerization indicates that the transition state has much more charge separation than the ground state. E-2 cannot be isomerized to Z-2 thermally but photochemically. On the other hand, $Z-2$ can be irreversibly isomerized back to $E-2$ thermally.

\section{Experimental Section}

General Procedures. Unless otherwise stated reagents were obtained from commercial suppliers and used as received. Ethyl (2-cyanoacetyl)carbamate, 1, was prepared according the literature method. $^{12}$ 
E-Ethyl (2-cyano-3-ethoxyacryloyl)carbamate (E-2). To a solution of $\mathbf{1}(0.156 \mathrm{~g}, 1 \mathrm{mmol})$ and acetic anhydride $(1 \mathrm{~mL})$ in $2 \mathrm{~mL}$ of chloroform was ethyl orthoformate $(0.296 \mathrm{~g}, 2 \mathrm{mmol})$ added. The mixture was refluxed at $80^{\circ} \mathrm{C}$ under nitrogen atmosphere for $2 \mathrm{~h}$. After the reaction was complete, the reaction mixture was cooled down and concentrated by rotary evaporator. Ether was poured into the reaction mixture and the mixture stayed in refrigerator for $12 \mathrm{hrs}$. After filtration of the mixture, white powder was collected and recrystallized from chloroform/ether. Yield: 75\%; ${ }^{1} \mathrm{H}$ NMR $\left(\mathrm{CD}_{3} \mathrm{CN}\right) \delta 1.23\left(3 \mathrm{H}, \mathrm{t}, \mathrm{CH}_{3}\right), 1.34\left(3 \mathrm{H}, \mathrm{t}, \mathrm{CH}_{3}\right), 4.12\left(2 \mathrm{H}, \mathrm{q}, \mathrm{CH}_{2}\right), 4.39$ $\left(2 \mathrm{H}, \mathrm{q}, \mathrm{CH}_{2}\right), 8.17(1 \mathrm{H}, \mathrm{s}, \mathrm{CH}), 9.12(1 \mathrm{H}, \mathrm{s}, \mathrm{NH}) ;{ }^{13} \mathrm{C} \mathrm{NMR}\left(\mathrm{CD}_{3} \mathrm{CN}\right) \delta 14.80,15.87,63.13$, 75.69, 89.30, 114.69, 152.22, 162.01, 175.13; IR (thin film) $2227(\mathrm{CN}), 1774,1689(\mathrm{C}=\mathrm{O}) \mathrm{cm}^{-1}$; MS (EI) m/z $212\left(4, \mathrm{M}^{+}\right.$), 118 (100), 88 (32), 74 (24), 57 (28); HRMS (EI) m/z calcd for $\mathrm{C}_{9} \mathrm{H}_{12} \mathrm{~N}_{2} \mathrm{O}_{4}$ 212.0797, found 212.0801.

\section{NMR study of isomerization between $E-2$ and $Z$-2}

Proton NMR spectra of a $\mathrm{CD}_{3} \mathrm{CN}$ solution $(0.5 \mathrm{~mL})$ of $E-2(0.01 \mathrm{mmol})$ were measured before ultraviolet irradiation, $5 \mathrm{~min}, 10 \mathrm{hrs}$, and 1 day after $2 \mathrm{hrs}$ irradiation at $254 \mathrm{~nm}$. The sample solution was transferred to a quartz flask with a sealed cap when it was subject to the ultraviolet irradiation.

\section{Kinetic studies for isomerization of $Z-2$ to $E$-2}

Kinetics for isomerization of Z-2 was carried out by ultraviolet absorption measurement of a sample solution at $\lambda=272 \mathrm{~nm}$, which was approximately $0.1 \mathrm{mM} \mathrm{E-2}$ solution in $\mathrm{CH}_{3} \mathrm{CN}$ and was subjected to $2 \mathrm{hrs}$ of ultraviolet irradiation at $254 \mathrm{~nm}$. Six different short periods of time, which is spaced evenly throughout the whole isomerization, was chosen for each of kinetic studies. The kinetic studies were carried out at $25,30,35,40$, and $45^{\circ} \mathrm{C}$, respectively, in the thermostatic UV cell with Perkin-Elmer Lambda 12 spectrophotometer. The plot of ultraviolet absorption vs. time was fitted with a first-order exponential rise by the SigmaPlot software to get a first-order rate constant. All rate constants were measured at least in duplicate with maximum deviations of $\pm 5 \%$.

\section{Acknowledgments}

Financial support by the National Science Council of Taiwan (NSC 92-2113-M-006-010) is gratefully acknowledged.

\section{References}

1. Ozaki, S. Medicinal Research Reviews 1996, 16, 51.

2. Dömling, A.; Ugi, I. Angew. Chem., Int. Ed. 2000, 39, 3168.

3. (a) Dugave, C.; Demange, L. Chem. Rev. 2003, 103, 2475. (b) Feringa, B. L. Acc. Chem. Res. 2001, 34, 504. (c) Tomasulo, M.; Sortino, S.; Raymo, F. M. Org. Lett. 2005, 7, 1109. (d) 
Pina, F.; Lima, J. C.; Parola, A. J.; Afonso, C. A. M. Angew. Chem., Int. Ed. 2004, 43, 1525. (e) Giordani, S.; Raymo, F. M. Org. Lett. 2003, 5, 3559. (f) van Delden, R. A.; Hurenkamp, J. H.; Feringa, B. L. Chem. Eur. J. 2003, 9, 2845.

4. (a) Kleinpeter, E.; Klod, S.; Rudorf, W.-D. J. Org. Chem. 2004, 69, 4317. (b) Fischer, G.; Rudorf, W.-D.; Kleinpeter, E. Magn. Reson. Chem. 1991, 29, 212. (c) Sandström, J. In Topics in Stereochemistry; Allinger, N. L.; Eliel, E. L.; Wilen, S. H.; Eds. John Wiley and Sons: New York, 1983; Vol. 14. (d) Markovic, R.; Baranac, M.; Jovanovic, V.; Dzambaski, Z. J. Chem. Edu. 2004, 81, 1026. (e) Sin, H. S.; Holler, M.; Burger, A.; Biellmann, J. F. Tetrahedron Lett. 1997, 38, 3585. (f) Zhu, S. Z.; Qin, C. Y.; Xu, G. L.; Chu, Q. L. Tetrahedron Lett. 1998, 39, 5265. (g) Abbotto, A.; Bradamante, S.; Capri, N.; Rzepa, H.; Williams, D. J.; White, A. J. Org. Chem. 1996, 61, 1770.

5. Silverstein, R.M. Webster FX. Spectrometric Identification of Organic Compounds, $6^{\text {th }}$ Edn; John Wiley \& Sons: New York, 1998.

6. Ceder, O.; Stenhede, U. Tetrahedron 1973, 29, 1585.

7. Connors, K. A. Chemical Kinetics. VCH Publishers: New York, 1990.

8. Carey, F. A.; Sundberg, R. J. Advanced Organic Chemistry, Part A: Structure and Mechanism, $2^{\text {nd }}$ Edn; Plenum Press: New York, 1984.

9. Grunwald, E.; Winstein, S. J. Am. Chem. Soc. 1948, 70, 846.

10. (a) Douglas, J. E.; Rabinovitch, B. S.; Looney, F. S. J. Chem. Phys. 1955, 23, 315. (b) Rabinovitch, B. S.; Michel, K.-W. J. Am. Chem. Soc. 1959, 81, 5056. (c) Kristiakovsky, G. B.; Smith, W. R. J. Am. Chem. Soc. 1934, 56, 638.

11. Forni, A.; Destro, R. Chem. Eur. J. 2003, 9, 5528.

12. Atkinson, M. R.; Shaw, G.; Warrener, R. N. J. Chem. Soc. 1956, 4118. 